\title{
Escala para detectar riesgos de accidente cerebrovascular en pacientes con ataque isquémico transitorio previo
}

Rothwell PM y col. Lancet 2005; 366: 29-36.

\section{Objetivo}

Validar una escala, llamada ABCD, para predecir el riesgo de accidente cerebrovascular (ACV) dentro de los siete días en pacientes con accidente isquémico transitorio (AIT).

\section{Diseño}

Desarrollo de una regla de predicción clínica*, y validación de la misma en otro grupo de pacientes, mediante la selección de variables predictoras de ACV.

\section{Lugar}

Departamento de Neurología Clínica, Universidad de Oxford, Reino Unido.

\section{Población}

La regla se generó en una cohorte de 209 pacientes con AIT probable o determinado provenientes del Oxfordshire Community Stroke Project (OCSP). Se validó en una población similar del Oxford Vascular Study (OXVASC) y en pacientes con sospecha de AIT referidos a los Servicios de Medicina y a una Clínica Especializada de AIT.

\section{Metodología}

Se desarrolló una escala de seis puntos para la predicción de la ocurrencia de ACV. Las variables incluidas en la escala y su puntaje respectivo, fueron el siguiente:

Edad mayor a 60 años $=1$

Presión arterial: mayor de $140 \mathrm{mmHg}$ de sistólica o mayor de 90 $\mathrm{mmHg}$ de diastólica $=1$

Clínica: debilidad unilateral $=2$; alteración del habla $\sin$ debilidad $=$ $1 ;$ otro $=0$

Duración de los síntomas: mayor a 60 minutos $=2$; entre 10 y $59=$ 1 ; menor de $10=0$

\section{Medición de resultados}

El evento primario fue ACV y su asociación con las variables descriptas previamente.

\section{Resultados}

El riesgo de ACV a siete días en las cohortes del OCSP y OXVASC fue del $8,6 \%$ y del $10,5 \%$, respectivamente. En la cohorte de ge- neración (OXVASC) 19 (95\%) de los 20 ACV que se presentaron dentro de los siete días ocurrieron en pacientes con una escala igual o mayor a cinco puntos. Los pacientes con una puntuación menor a cinco puntos tuvieron un riesgo de $0,4 \%$ (IC95\% 0-1,1) con cinco el riesgo fue de $12,1 \%(4,2-20)$ y con seis fue de $31,4 \%$ (1646,8 ). El área bajo la curva ROC* fue de 0,91 (IC 95\% 0,86-0,95).

Riesgo de accidente cerebrovascular a siete días en la cohorte de generación de la regla (OXVASC)

\begin{tabular}{c|c|c|c}
\hline Escala ABCD & Pacientes (\%) & ACV (\%) & $\%$ de riesgo (IC 95\%) \\
\hline Menor 0 igual 1 & $28(7 \%)$ & 0 & 0 \\
\hline 2 & $74(20 \%)$ & 0 & 0 \\
\hline 3 & $82(22 \%)$ & 0 & 0 \\
\hline 4 & $90(24 \%)$ & $1(5 \%)$ & $1.2(0-3,3)$ \\
\hline 5 & $66(18 \%)$ & $8(40 \%)$ & $12.3(4,-20,0)$ \\
\hline 6 & $35(9 \%)$ & $11(55 \%)$ & $31.4(16,0-46,8)$ \\
\hline Total & $375(100 \%)$ & $20(100 \%)$ & $5,3(3,0-7,5)$ \\
\hline
\end{tabular}

Riesgo de accidente cerebrovascular a siete días en la cohorte de validación de la regla (Clínica de AIT)

\begin{tabular}{c|c|c|c}
\hline Escala ABCD & Pacientes (\%) & ACV (\%) & $\%$ de riesgo (IC 95\%) \\
\hline Menor o igual 1 & $18(9 \%)$ & 0 & 0 \\
\hline 2 & $36(18 \%)$ & 0 & 0 \\
\hline 3 & $40(20 \%)$ & 0 & 0 \\
\hline 4 & $55(26 \%)$ & $5(36 \%)$ & $9,1(1,5-16,7)$ \\
\hline 5 & $34(16 \%)$ & $4(29 \%)$ & $11,8(0,9-2,6)$ \\
\hline 6 & $23(11 \%)$ & $5(36 \%)$ & $23,8(5,6-6-2,0)$ \\
\hline Total & $206(100 \%)$ & $14(100 \%)$ & $6,7(3,3-10,0)$ \\
\hline \multicolumn{4}{|l}{}
\end{tabular}

\section{Conclusión}

Aunque futuras validaciones y correcciones de la escala $A B C D$ serán necesarias, la misma puede ser utilizada en la práctica clínica para identificar a los pacientes de alto riesgo de ACV luego de un AIT. Aquellos pacientes con un puntaje de cinco o más tienen riesgo elevado de padecer ACV dentro de los siete días.

\section{Comentario}

Los pacientes con AIT presentan hasta un $10 \%$ de riesgo de padecer un ACV dentro de los siguientes siete días en estudios poblacionales y en registros hospitalarios ${ }^{1}$. Existen diversos modelos para predecir el riesgo de ACV en pacientes con AIT a mediano y largo plazo. Sin embargo el riesgo precoz de presentar un evento vascular definitivo se encuentra pobremente estudiado ${ }^{2}$. Actualmente se sabe que el $90 \%$ de los ACV ocurre en personas mayores de 60 años y que la hipertensión arterial es el principal factor de riesgo en está población ${ }^{3}$. En relación con los AIT las nuevas técnicas por imágenes (Difusión -ADC Map) permitieron demostrar que cuando la duración de los síntomas es mayor a 60 minutos, o el paciente presenta síntomas motores o compromiso del lenguaje, la incidencia de lesiones isquémicas definitivas es mayor. Estos datos llevan a proponer una nueva definición de AIT, en la cual los síntomas deberán resolverse en menos de una hora y las imágenes de resonancia magnética demostrar la ausencia de eventos isquémicos en las secuencias de difusión.

\section{Conclusiones del comentador}

La Escala ABCD para predecir el riesgo de ACV dentro de los primeros siete días en pacientes con AIT puede constituirse en un elemento más en la evaluación clínica inicial. La presencia de un puntaje mayor o igual a cinco representa un riesgo aumentado de presentar un evento definitivo, y los pacientes deberán ser ingresados al hospital para completar estudios diagnósticos e instaurar el tratamiento.

Mara Cristina Zurru [ Médica Especialista en Neurología. Servicio de Neurología. Hospital Italiano de Buenos Aires. ]

* ver glosario

Zurrú M. Una escala simple puede detectar riesgos tempranos de accidente cerebrovascular en pacientes con ataque isquémico transitorio previo. Evid. actual. práct. ambul. 2006;9(4):109. Jul-Ag 2006. Comentado de: Rothwell PM, Giles MF, Flossmann E, y col. A simple score (ABCD) to identify individuals at high early risk of stroke after transient ischaemic attack. Lancet 2005; 366: 29-36. PMID: 15993230.

\section{Referencias}

1. Rothwell PM. Incidence, risk factors and prognosis of stroke and transient ischaemic attack the need for high-quality large-scale epidemiological studies. Cerebrovascular Disease 200316 (suppl 3): 2-10.

2. Lovett J, Dennis M, Sandercock PAG, et al. The very early risk of stroke following a TIA. Stroke. 2003; 34: 38-e40.

3. Rothwell PM, Coull A, Giles M, et al. Changes in stroke incidence mortality, case-fatality, severity and risk factors in Oxfordshire from 1981-2004: the Oxford Vascular Study. Lancet 2004; 363:1925-33. 